\title{
In Vitro Effects of Ivermectin and Sulphadiazine on Toxoplasma gondii
}

\author{
Melek Bilgin', Tuba Yıldırım², Murat Hökelek ${ }^{3}$ \\ ${ }^{1}$ Microbiology Laboratory, Samsun Education and Research Hospital, Samsun, Turkey \\ ${ }^{2}$ Department of Biology, Faculty of Arts and Sciences, Amasya University, Amasya, Turkey \\ ${ }^{3}$ Department of Medical Microbiology, Cerrahpaşa Faculty of Medicine, Istanbul University, İstanbul, Turkey
}

\begin{abstract}
Objective: Ivermectin and sulphadiazine were tested individually to determine their in vitro effects on Toxoplasma gondii grown in human epidermoid larynx carcinoma (Hep-2) cell culture.

Study Design: In-vitro study.

Material and Methods: Toxoplasma growth was quantities by an enzyme immunoassay performed directly on the fixed cultures, using a rabbit anti-T. gondii immunoglobulin $\mathrm{G}$ as the first antibody and a phosphatase-labeled anti-rabbit immunoglobulin $\mathrm{G}$ as the second antibody. For each drug, regres-
\end{abstract} sion models were used to quantify the relationship between optical density values and antimicrobial agent concentrations in the cultures.

Results: The $50 \%$ inhibitory concentrations (IC50) of ivermectin and sulphadiazine were found to be $0.2 \mu \mathrm{g} / \mathrm{mL}$ and $7.3 \mu \mathrm{g} / \mathrm{mL}$ after $48 \mathrm{~h}$ of exposure, respectively. None of the concentrations tested for each drugs demonstrated toxicity to Hep-2 cells after $72 \mathrm{~h}$ of incubation.

Conclusion: These results indicate that ivermectin significantly inhibited replication of the tachyzoites of T. gondii RH strain.

Key Words: Toxoplasma gondii, ivermectin, sulphadiazine, in vitro, Hep-2

Received: 13.06 .2012

Accepted: 04.10.2012

\section{Introduction}

Toxoplasma gondii is a protozoan parasite that infects up to a third of the world's population. In most individuals, acute infection with T. gondii is asymptomatic or causes mild symptoms. However, toxoplasmosis can cause severe diseases in fetuses if a seronegative pregnant woman is infected. Toxoplasmosis can also be fatal in immunodeficiency or immunocompromised individuals $(1,2)$.

The combination of sulphadiazine (SDZ) and pyrimethamine is frequently used for the treatment of $T$. gondii infections. These drugs have a remarkable synergistic activity against the replicating form of $T$. gondii through the sequential inhibition of parasite dihydropteroate synthase (DHPS) and dihydrofolate reductase (DHFR) (3). However, treatment fails to eliminate the encysted form of the parasite. Furthermore, treatment with these agents is associated with frequent and severe adverse reactions, especially in patients with acquired immunodeficiency syndrome (4). The development of new alternatives to sulphadiazine and pyrimethamine therapy requires better knowledge of the effects of antimicrobial agents on T. gondii.

Recently, Merli et al. (5) developed an enzyme immunoassay for evaluation of Toxoplasma growth in tissue culture and suggested its application to study the in vitro activity of anti-T. gondii compounds. With this method, the relationship between the inhibitory effect of a drug and its concentration in the culture medium can be determined by regression analysis (6).
The aim of this study was to investigate the in vitro antiToxoplasma activities of antiparasitic ivermectin and sulphadiazine, currently one of the most effective available therapeutic agents, using tachyzoit of $T$. gondii $\mathrm{RH}$ strain infected Hep-2 epithelial cells. For this purpose, Hep-2 cells in tissue culture plates were infected with tachyzoites isolated from peritoneal fluid of mice infected with T. gondii. Subsequently, ivermectin or sulphadiazine was added. Inhibitory activity was assessed after $24 \mathrm{~h}, 48 \mathrm{~h}$ and $72 \mathrm{~h}$ incubations using invert microscopy and at $48 \mathrm{~h}$ by enzyme-linked immunosorbent assay (ELISA). The toxicities of ivermectin, sulfadiazine and tachyzoit to Hep2 cells were determined with Neutral Red Uptake (NRU) assay.

\section{Material and Methods}

\section{Cultures of T. gondii \\ (i) Cells}

Hep-2 (An1-92041501; Institute of Foot and Mounts Diseases, Virology Laboratory, Ankara, Turkey) were maintained in Minimum Essential Medium Eagle (MEM) (Sigma, Steinheim, Germany) containing penicillin (100 IU/mL), streptomycin $(0.1 \mathrm{mg} / \mathrm{mL}$ ) (Biochrom, Leonorenstr, Berlin), and $5 \%$ heat-inactivated fetal bovine serum (FBS) (Biochrom, Leonorenstr, Berlin). For the assays, Hep-2 cultures were prepared in 96-well cell culture plates (TPP, Switzerland). The cells were seeded onto each well $\left(2.0 \times 10^{4}\right.$ cells per well) and grown to confluence at $37^{\circ} \mathrm{C}$ in a moist $5 \% \mathrm{CO}_{2}-95 \%$ air atmosphere. 


\section{(ii) Parasites}

Tachyzoites of the virulent TR-RH strain maintained through serial intraperitoneal of mice passages were used. For experimental infections, tachyzoites were harvested from the peritoneal fluid of mice infected intraperitoneally 2-4 days earlier and purified by centrifugation. The parasites were washed with MEM. They were counted and adjusted to a concentration of $5.0 \times 10^{4}$ parasites per $\mathrm{mL}$.

\section{(iii) Challenging the cultures}

For the assays with antimicrobial agents, confluent monolayers were inoculated with $100 \mu \mathrm{L}$ of the parasite suspension, i.e., 5000 trophozoites. This inoculum dose was determined in a preliminary experiment in which various parasite inputs concentrations $\left(2.0 \times 10^{5}, 1.0 \times 10^{5}, 5.0 \times 10^{4}, 2.0 \times 10^{4}, 1.0 \times 10^{4}\right.$, $5.0 \times 10^{3}, 2.0 \times 10^{3}$ and $1.0 \times 10^{3}$ parasites per well) were compared. The inoculums of $5.0 \times 10^{3}$ parasites were found to be optimum for long incubation times. The cultures could be maintained up to $72 \mathrm{~h}$ after challenge, and infected monolayers were fully preserved for ELISA.

Three controls were included in each culture plate: (i) uninfected monolayers as a negative control, (ii) infected monolayers in which the replication of $T$. gondii was inhibited by the addition of $50 \mu \mathrm{L}$ of $0.25 \%$ sodium azide (Serva, Heidelberg Carl-Benz-Str) per well at $4 \mathrm{~h}$ after challenge (inoculum's controls), and (iii) infected monolayers with culture medium alone as a positive control. After development of the coloration, spectrophotometric readings were performed at a $\lambda$ of $450 \mathrm{~nm}$ using blanks (negative control) in addition to all two controls. The results were expressed as optical density values. Experiments were repeated two times and were duplicated for each drug dose.

\section{Quantitation of T. gondii growth in cultures}

For quantitation of T. gondii growth in the culture, the supernatant was removed by aspiration. The monolayers were fixed with cold methanol for $15 \mathrm{~min}$ and air dried.

\section{Antimicrobial agents}

Sulphadiazine (Sigma, Steinheim, Germany) was initially dissolved in 50\% methanol-50\% acetone (Riedel-de Haën, Germany) at a concentration of $2000 \mu \mathrm{g} / \mathrm{mL}$. Ivermectin (Sigma, Steinheim, Germany) was dissolved in dimethyl sulfoxide (DMSO) (Sigma, Steinheim, Germany) at a concentration of $1600 \mu \mathrm{g} / \mathrm{mL}$.

Antimicrobial agents were added to the culture $4 \mathrm{~h}$ after challenge with T. gondii. For each antimicrobial agent, serial dilutions were prepared in MEM-FBS so that the addition of a $100 \mu \mathrm{L}$ amount to the culture yielded the following final concentrations: SDZ, $0.7,0.15,0.3,0.6,12.5,25,50$, and $100 \mu \mathrm{g} / \mathrm{mL}$; ivermectin, $0.035,0.07,0.15,0.3,0.6,1.25,2.5$ and $5 \mu \mathrm{g} / \mathrm{mL}$. Each concentration was tested in eight replicate wells. Preliminary studies indicated that final concentrations of methanol and acetone in dilution of SDZ did not inhibit the growth of T. gondii. Cultures were incubated with antimicrobial agents up to $72 \mathrm{~h}$ after challenge and cultures were examined microscopically, and then fixed with methanol, air dried, and stored at $+4^{\circ} \mathrm{C}$, and ELISA was performed as described.

\section{ELISA}

An ELISA test was performed directly on the tissue culture test plates (TPP, Switzerland) by using (i) anti-T. gondii antibodies (immunoglobulin G fraction) (Abcam Inc, Kendall Square Stc, Cambridge/USA) as the first antibody and (ii) anti-rabbit immunoglobulin $\mathrm{G}$ (whole molecule) alkaline phosphatase antibody produced in goat (Sigma A3687, Steinheim, Germany) as the second antibody. Wells were postcoated with $200 \mu \mathrm{L}$ of phosphate-buffered saline (PBS)-0.5\% Tween $20-1 \%$ bovine serum albumin (Sigma, Steinheim, Germany) (PBS-T-BSA) for 1 $h$ at $37^{\circ} \mathrm{C}$ to block nonspecific adsorption sites. The plates were washed five times with PBS containing $0.5 \%$ Tween 20 and then $100 \mu \mathrm{L}$ of anti-Toxoplasma antibodies diluted 1/100 in PBS-TBSA was added to the wells. Plates were incubated for $120 \mathrm{~min}$ at $37^{\circ} \mathrm{C}$ and then washed as described above. A $100 \mu \mathrm{L}$ sample of the conjugate diluted $1 / 1000$ in PBS-T-BSA was added, and the plates were incubated for $60 \mathrm{~min}$ at $37^{\circ} \mathrm{C}$. After the plates were washed five times, $100 \mu \mathrm{L}$ of paranitrophenyl phosphate (Sigma, Steinheim, Germany) $1 \mathrm{mg} / \mathrm{mL}$ in substrate solution (0.1 M Glisin, $5 \mathrm{M} \mathrm{KOH,} 1 \mathrm{mM} \mathrm{MgCl}, 1 \mathrm{mM} \mathrm{ZnCl}_{2}, \mathrm{pH}: 10.4$ ) (Sigma, Steinheim, Germany) was added, and the plates were incubated for $30 \mathrm{~min}$ at room temperature. For reading with a Microplate Reader (Rayto, RT-2100c) was used at $450 \mathrm{~nm}$. The negative control wells were used as the blanks. The results were expressed as optical density (OD) values.

To assess the cytopathic effects and the reproduction of intracellular T. gondii tachyzoites and control cells in $24 \mathrm{~h}, 48$ $\mathrm{h}$ and $72 \mathrm{~h}$; the coverslips on 24 well tissue culture plates were stained with Giemsa and examined microscopically (Figure 1).

The plates prepared with 8 different concentrations of sulphadiazine and ivermectin were examined microscopically after $24 \mathrm{~h}, 48 \mathrm{~h}$ and $72 \mathrm{~h}$.

\section{Statistical analysis}

A correlation coefficient was used to quantify the relationship between $T$. gondii counts and ELISA results. The effect of antimicrobial agents at various concentrations was described by data plotting. Optical density was plotted as a function of the logarithm of the concentration, which suggested models summarizing the concentration effect. Regression analysis was used to quantify the relationship between optical density values and antimicrobial agent concentrations in the cultures (6).

\section{Results}

The present study, after the microscopic examination of the plates it was determined that there were no inhibitory effects at all concentrations for ivermectin in $24 \mathrm{~h}$. At $48 \mathrm{~h}$ the number of tachyzoites decreased relative to control wells at $0.31,0.62$ and $1.25 \mu \mathrm{g} / \mathrm{mL}$. An important inhibitory effect was observed at 2.5 and $5 \mu \mathrm{g} / \mathrm{mL}$. This inhibition of growth was associated with a reduction of the number of parasitized cells and intracellular parasites that were morphologically normal. In $72 \mathrm{~h}$, because of the number of tachyzoites elevated in all wells, the inhibitory effect of ivermectin was not assessed except at 2.5 and $5 \mu \mathrm{g} / \mathrm{mL}$ concentrations.

For sulphadiazine, as for ivermectin, at $24 \mathrm{~h}$ there were no inhibitory effects at all concentrations tested. At $48 \mathrm{~h}$, the 


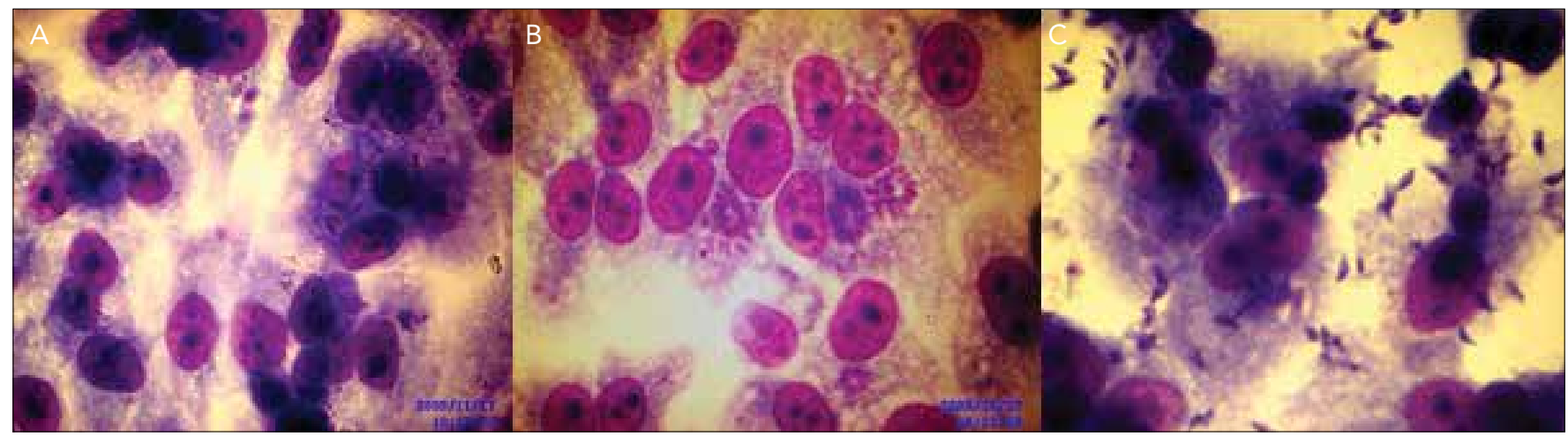

Figure 1. Reproduction of intracellular T. gondii tachyzoites A. one- two tachyzoites in $24 \mathrm{~h}, \mathrm{~B}$. parasites formed rosettes or large pseudocysts in $48 \mathrm{~h}, \mathrm{C}$. free tachyzoites in extracellular fluid in $72 \mathrm{~h}$

number of tachyzoites had decreased relative to control wells at $3.12,6.25,12.5$ and $25 \mu \mathrm{g} / \mathrm{mL}$. An important inhibitory effect was observed at 50 and $100 \mu \mathrm{g} / \mathrm{mL}$. In $72 \mathrm{~h}$, because of the number of tachyzoites elevated in all wells, the inhibitory effect of sulphadiazine was not assessed. Therefore, ELISA was performed directly on the culture plates at $48 \mathrm{~h}$. The ELISA did not alter the structure of fibroblasts.

\section{Effect of antimicrobial agents}

For each antimicrobial agent, experimental OD values were plotted versus concentrations. Regression lines results are shown in Figure 2.

\section{Sulphadiazine}

Sulphadiazine in all concentration, except at a concentration of 0.75 and $1.5 \mu \mathrm{g} / \mathrm{mL}$ ( $p>0.05$ ) showed significantly higher inhibitory activity against tachyzoites after $48 \mathrm{~h}$ incubations. The $50 \%$ inhibitory concentrations $\left(\mathrm{IC}_{50}\right)$ of sulphadiazine was estimated to be $7.3 \mu \mathrm{g} / \mathrm{mL}[O D=451.75-54.29$ in concentration (c)] after $48 \mathrm{~h}$ of exposure. None of the concentrations tested for each drug demonstrated toxicity to Hep-2 cells after $72 \mathrm{~h}$ of incubation.

\section{Ivermectin}

Ivermectin was found to have significant inhibitory activity against tachyzoites after $48 \mathrm{~h}$ of incubation at a concentration of 2.5 and $5 \mu \mathrm{g} / \mathrm{mL}(p<0.01)$ and above dose. The $50 \% \mathrm{IC}_{50}$ of ivermectin was estimated to be $0.27 \mu \mathrm{g} / \mathrm{mL}[\mathrm{OD}=358.38$ $23.35 \ln (\mathrm{c})]$ after $48 \mathrm{~h}$ of exposure. None of the concentrations tested for each drugs demonstrated toxicity to Hep-2 cells after $72 \mathrm{~h}$ of incubation.

\section{Discussion}

An ELISA performed directly on tissue culture was used to quantify the growth of T. gondii in Hep-2 fibroblasts. This assay was performed as described by Merli et al. (5) who initially showed that an ELISA performed on infected cells was a reliable method for studying $T$. gondii growth kinetics in tissue culture. Therefore, this method was used to evaluate the inhibitory effect of antimicrobial agents. The assessment was based on the relationship between OD values and log concentrations of antimicrobial agents in the cultures as shown by regression analysis in Figure 2.
Diab and El-Bahy (7) determined that the Hep-2 cell line appeared to be the most appropriate cell line for in vitro multiplication of $T$. gondii ( $\mathrm{RH}$ strain) in maintenance media with or without fetal calf sera at different temperatures. Therefore, Hep-2 cell line was used in this assay.

With SDZ, we found a significant inhibitory effect for concentrations of 25,50 and $100 \mu \mathrm{g} / \mathrm{mL}(\mathrm{p}<0.001)$; a slight inhibitory effect for $3.12,6.25,12.5 \mu \mathrm{g} / \mathrm{mL}(p<0.01)$ and no inhibitory effect for 0.75 and $5 \mu \mathrm{g} / \mathrm{mL}(\mathrm{p}>0.05)$ at $48 \mathrm{~h}$ incubation. The $50 \% I_{50}$ of sulphadiazine was estimated to be $7.3 \mu \mathrm{g} / \mathrm{mL}$ $[O D=451.75-54.29 \ln (\mathrm{c})]$ after $48 \mathrm{~h}$ of exposure.

Similarly, Derouin and Chastang (6) investigated the in vitro inhibitory effect of antimicrobial agents on T. gondii grown on MRC5 fibroblasts. In their study, sulfadoxine was not found inhibitory at concentrations from 2 to $20 \mu \mathrm{g} / \mathrm{mL}$. An inhibitory effect was observed at $30 \mu \mathrm{g} / \mathrm{mL}(\mathrm{p}<0.001)$. Within the interval between 30 and $75 \mu \mathrm{g} / \mathrm{mL}$, the inhibitory effect could be summarized by a linear function of the concentration $[O D=2.35$ $0.5 \ln (\mathrm{c})]$. For higher concentrations, the inhibitory effect did not significantly increase.

In a study Meneceuri et al. (8) investigated the in vitro susceptibility of various genotypic strains of $T$. gondii to pyrimethamine, sulphadiazine and atovaquone. In their study they examined SDZ at 10 concentrations ranging between 0.0005 and $100 \mathrm{mg} /$ liter. SDZ was inhibitory for 13 strains, with $\mathrm{IC}_{50}$ ranging between 3 and $18.9 \mathrm{mg} / \mathrm{L}$.

Derouin and Chastang (9) investigated the in vitro effects of folate inhibitors on T. gondii grown in MRC5 fibroblast tissue culture found that three sulfonamides and four dihydrofolate reductase inhibitors have important inhibitory effects on T. gondii. They studied sulphadiazine at $0.001,0.01,0.05,0.1$, $0.2,0.5,2,10$, and $20 \mu \mathrm{g} / \mathrm{mL}$ concentrations, the \%50 inhibitory concentration estimated from the regression model was $2.5 \mu \mathrm{g} / \mathrm{mL}$ for sulphadiazine.

Ivermectin is a derivative of the avermectins, a family of macrocyclic lactones produced by the filamentous bacterium Streptomyces avermitilis. With ivermectin, we found a significant inhibitory effect for concentrations 2.5 and $5 \mu \mathrm{g} / \mathrm{mL}$ $(p<0.001)$, and a slight inhibitory effect for $0.15,0.3,0.6$ and $1.25 \mu \mathrm{g} / \mathrm{mL}(p<0.01)$ and no inhibitory effect for 0.035 and $0.07 \mu \mathrm{g} / \mathrm{mL}(\mathrm{p}>0.3)$ at $48 \mathrm{~h}$ incubation. The $50 \% \mathrm{IC}_{50}$ of ivermectin was estimated to be $0.27 \mu \mathrm{g} / \mathrm{mL}[\mathrm{OD}=358.38-23.35$ $\ln (\mathrm{c})]$ after $48 \mathrm{~h}$ of exposure. Our in vitro results obtained with 


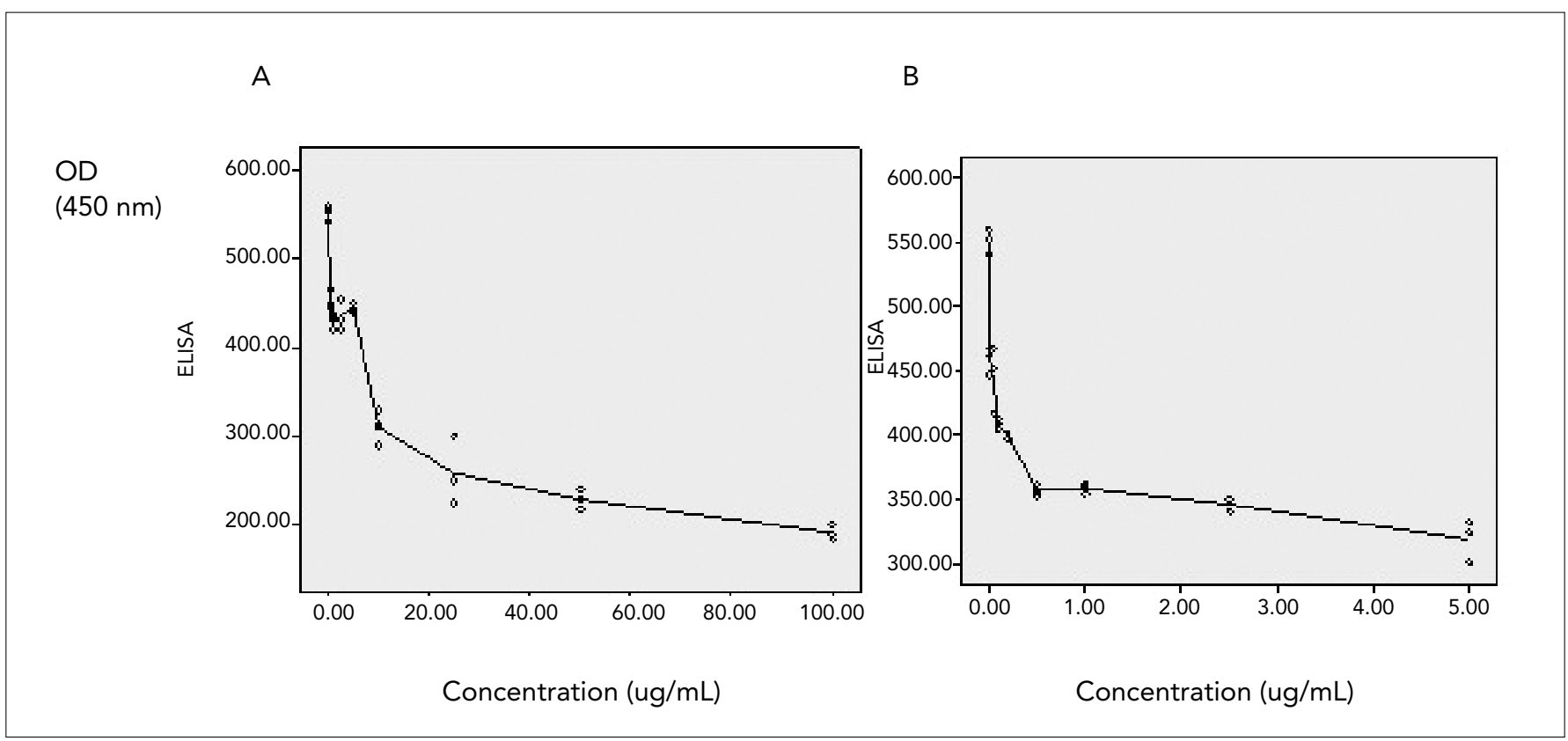

Figure 2. $O D_{450}$ values for the ELISA with infected monolayers versus concentrations of antimicrobial agents. $y$ axis, $\mathrm{OD}_{450}$ values; $x$ axis, concentration of antimicrobial agent. A. SDZ, B. Ivermectin

ivermectin are in agreement with the studies performed by Guzzo et al. (10).

Our results indicated that ivermectin significantly inhibited replication of the tachyzoites of $T$. gondii $\mathrm{RH}$ strain. Therefore, the present study results may be useful for further studies in combination with other drugs and animal models to develop a better treatment model for toxoplasmosis in humans.

Ethics Committee Approval: Ethics committee approval was received from Ondokuz Mayıs University Faculty of Medicine for this study (28.06.2006, HEK 225).

Informed Consent: N/A.

Peer-review: Externally peer-reviewed.

Author contributions: Concept - M.B.; Design - M.B.; Supervision T.Y.; Resource - M.B.; Materials - M.B.; Data Collection\&/or Processing - M.B.; Analysis\&/or Interpretation - M.H.; Literature Search - T.Y.; Writing - M.B., T.Y., M.H.; Critical Reviews - M.B., T.Y., M.H.

Conflict of Interest: No conflict of interest was declared by the authors.

Financial Disclosure: No financial disclosure was declared by the authors.

\section{References}

1. Montaya JG, Liesenfeld O. Toxoplasmosis. The Lancet 2004;363:1965-76. [CrossRef]
2. Montoya JG, Kovacs JA, Remington JS. Toxoplasma gondii. In:Mandell GL, Bennett JE, Dolin R, editors. Mandell, Douglas and Bennett's Principles and Practice of Infectious Diseases. 6th ed. Philadelphia:Elsevier Press;2008. p.3170-92.

3. Wilson $\mathrm{M}$, Jones LJ, McAuley LB. Toxoplasma. In:Murray PR, Baron EJ, Jorgensen JH, Landry ML, Pfaller MA, editors. Manual of Clinical Microbiology. 9th ed. Washington:ASM Press;2005. p.2070-81.

4. Petersen E. Toxoplasmosis. Seminars in Fetal \& Neonatal Medicine 2007;12:214-23. [CrossRef]

5. Merli A, Canessa A, Melioli G. Enzyme immunoassay for evaluation of Toxoplasma gondii growth in tissue culture. J Clin Microbiol 1985;21:88-91.

6. Derouin F, Chastang C. Enzyme Immunoassay to assess effect of antimicrobial agents on Toxoplasma gondii in tissue cultures. Antimicrob Agents Chemother 1988;32:303-7. [CrossRef]

7. Diab MR, El-Bahy MM. Toxoplasma gondii:Virulence of tachyzoites in serum free media at different temperatures. Exp Parasitol 2008;118:75-9. [CrossRef]

8. Meneceuri P, Bouldouyre MA, Aubert D, Villena I, Menotti J, Sauvage $V$, et al. Toxoplasma gondii:In vitro susceptibility of various genotypic strains to pyrimethamine, sulphadiazine and atovaquone. Antimicrob Agents Chemother 2008;52:1269-77. [CrossRef]

9. Derouin $F$, Chastang $C$. In vitro effects of folate inhibitors on Toxoplasma gondii. Antimicrob Agents Chemother 1989;33:1753-9. [CrossRef]

10. Guzzo CA, Furtek $\mathrm{Cl}$, Chen $\mathrm{C}$, Tipping R, Clineschmidt CM, Sciberras DG, et al. Safety, tolerability, pharmacokinetics of escalating high doses of ivermectin in healthy adult subjects. J Clin Pharmacol 2002;42:1122-33. [CrossRef] 